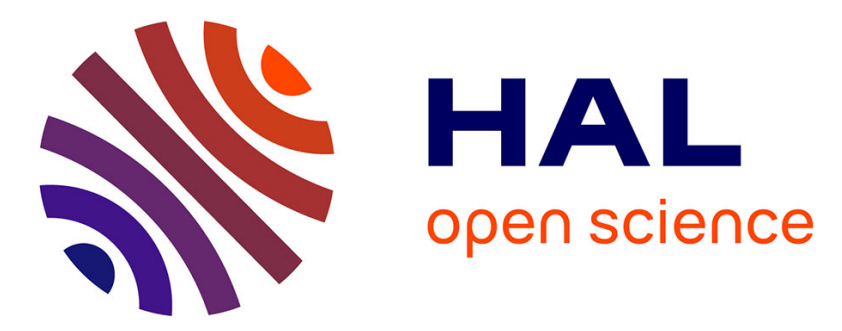

\title{
Performance Analysis of the Quality of Products for Value-Adding Processes in Virtual Enterprises
}

\author{
Hendrik Jähn, Thomas Burghardt
}

\section{To cite this version:}

Hendrik Jähn, Thomas Burghardt. Performance Analysis of the Quality of Products for Value-Adding Processes in Virtual Enterprises. 13th Working Confeence on Virtual Enterpries (PROVE), Oct 2012, Bournemouth, United Kingdom. pp.559-567, 10.1007/978-3-642-32775-9_56 . hal-01520452

\section{HAL Id: hal-01520452 \\ https://hal.inria.fr/hal-01520452}

Submitted on 10 May 2017

HAL is a multi-disciplinary open access archive for the deposit and dissemination of scientific research documents, whether they are published or not. The documents may come from teaching and research institutions in France or abroad, or from public or private research centers.
L'archive ouverte pluridisciplinaire HAL, est destinée au dépôt et à la diffusion de documents scientifiques de niveau recherche, publiés ou non, émanant des établissements d'enseignement et de recherche français ou étrangers, des laboratoires publics ou privés. 


\title{
Performance Analysis of the Quality of Products for Value-Adding Processes in Virtual Enterprises
}

\author{
Hendrik Jähn, Thomas Burghardt \\ Chemnitz University of Technology, Dept. of Economic Sciences, Thüringer Weg 7 \\ 09126 Chemnitz, Germany \\ hendrik.jaehn@wirtschaft.tu-chemnitz.de
}

\begin{abstract}
This contribution introduces one integral part of a comprehensive approach for the performance management in virtual enterprises by focusing the influencing factor "product quality" as one major performance parameter. This approach introduced as a meta-model is based on a value-adding processrelated perspective and implies a sophisticated analysis regarding the origin of quality level deviations. In order to apply the approach, it is necessary to consider the specific structure of the cooperation. In this paper at first some important details on the conditional circumstances are explained. This includes the performance analysis approach and a short literature review. This is followed by a description of general requirements for modeling the approach. In the main section, the approach is explained in detail.
\end{abstract}

Keywords: Performance Analysis, Quality, Value-Added Process, Virtual Enterprise

\section{Introduction}

In most cases, the agreement of a well-defined quality level represents an integral part of a contract between supplier and customer. Adherence to the agreed quality level should have the highest priority as deviations often entail far-reaching consequences. It may result in negative consequences for the supplier, e.g. in form of contractual penalties or loss of reliance and thus loss of customers. With regard to virtual enterprises, adherence to a quality level of a product takes on even greater significance when there is a particularly close and time-referenced cooperation. Here, deviations from the agreed product quality represents a serious problem area as reworking time can hardly be planned and can, thus, often lead to a delayed delivery.

The performance analysis of quality represents a valuable tool for an operative analysis. The performance parameter "quality" is based on different criteria that are evaluated separately. The findings are integrated into the overall result according to their relevance by applying specific weightings. Special attention is paid due to the fact that hardly any practicable quantitative-oriented approaches exist in theory or practice. However, this form of modeling represents an essential precondition for the value-added related performance analysis. Therefore, this subject matter is seized on and a solution approach is introduced in detail in the next sections of this contribution. 


\section{Surrounding Conditions}

The quantitative analysis of the influencing factor "product quality" within networked production structures such as virtual enterprises is embedded into a specific framework. In the following an approach here for is introduced. That comprehensive framework has been developed for the realization of a comprehensive performance analysis based on quantitative data [1]. It both includes value-adding process neutral and value-adding process-related process steps. The structure of the approach and the interdependencies of the components and process steps are displayed in fig.1.

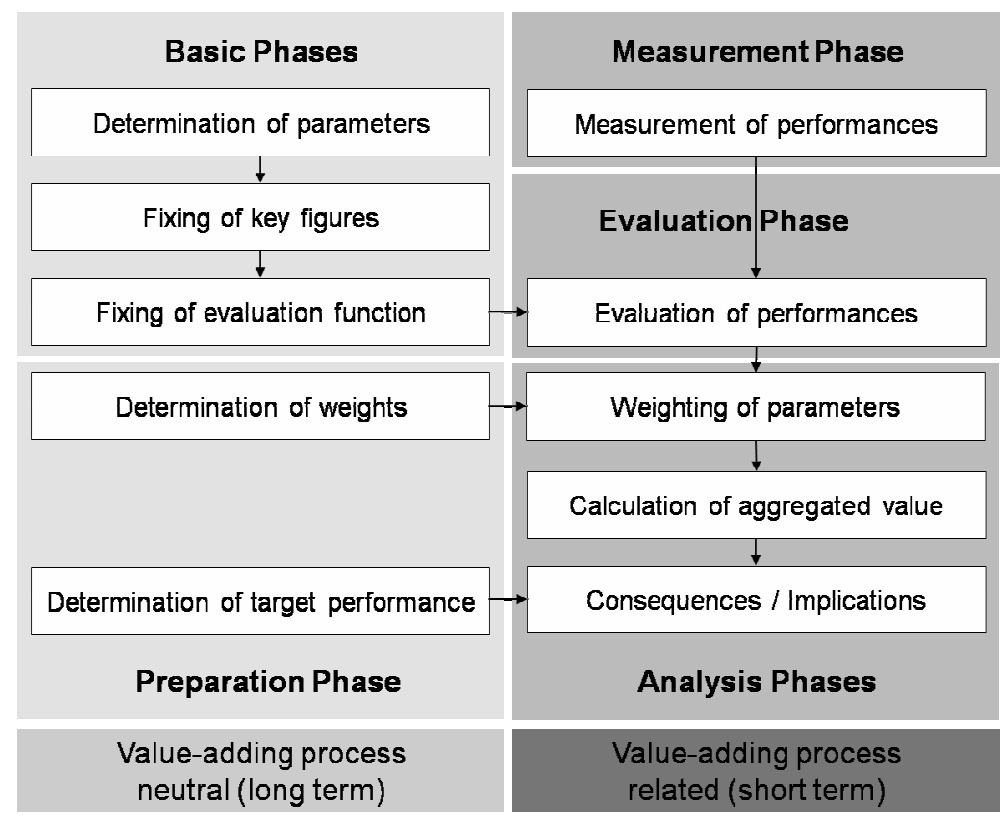

Fig. 1. Performance Analysis Approach

The performance analysis approach includes the measurement, evaluation and analysis of selected performance parameters identified by a modified Balanced Scorecard [2]. Herein, special attention is paid to aspects related to one specific selected value-adding process. This operational perspective allows acquiring cognitions about the degree the performance by an enterprise after finishing a specific value-adding process. Hereby, consequences, e.g. concerning the allocation of profit shares, can be deduced in case of an unsatisfactory performance of an enterprise [1]. The primary task of the performance analysis approach is to determine the degree of services performed by an enterprise. For this purpose, primarily quantitative methods are applied. The result is accounted for by the implementation of incentive and sanction mechanisms [2].

The determination of performance parameters is realized by the involvement of an adapted Balanced Scorecard approach. Performance parameters considered within the performance analysis are price, date of delivery, response time, product quality, 
reliance and cooperation climate [1],[2]. The last two parameters constitute soft-facts whose perceptions primarily have to be quantified through appropriate methods. Each of these performance parameters is characterized by a specific key figure. For the evaluation of the services performed, specific evaluation functions, similar to utility functions, are applied. In order to regard their different relevancies, the evaluations are weighted individually. By multiplying weighting and level of utility, aggregated utility values are calculated. The sum of the aggregated utilities of all performance parameters represents the actual performance. This can be compared to the target performance. Hereof, an enterprise-specific degree of target fulfillment is calculated. This allows a deviation of consequences. Next, the procedural method of the performance analysis approach is demonstrated in detail by considering the performance parameter "product quality".

Within the framework of a comprehensive approach for the enterprise-related performance analysis, the aim is to quantitatively analyze the degree of service provision. This means that a deviation of the realized from the agreed quality level needs to be recorded correctly and under consideration of the origin. Within networked production structures the problem is even more complex because there exists more than one upstream or downstream company. Here, monitoring and workflow management instruments need to be applied. Subsequently, the evaluation and the analysis are implemented by an adapted form of the value benefit analysis in combination with selected mathematical methods.

Approaches for the evaluation of performances within networked organization structures or supply chains exist in vast numbers and have been published in quite an uncountable quantity. It is impossible to mention all relevant publications. For that reason only a few publications are introduced which had a higher relevancy on the development of the approach. One forerunner is Neely, who deals with questions concerning the performance measurement in supply chains and networks [3]. Also Lynons et al. focus methodologies of the performance measurement in supply chains [4]. Herein, analyses can be made out of several perspectives [5]. In general, however, it has been observed that primarily medium- and long-term approaches are suggested. The background for this is the financial focus with regard to external effects of an enterprise. The development of these approaches is often reverted to the adoption of the Balanced Scorecard considering supply chains or networks [6],[7],[8]. A different perspective is introduced by Westphal et al. by investigating methodologies of measuring the performance in virtual enterprises [9]. However, this primarily represents a soft-fact and is, therefore, less relevant here. One of the few publications considering quality explicitly as one part of performance management is composed by Lockamy [10]. He stresses the necessity to research in this area by introducing a model for the development of quality-focused performance measurement systems.

\section{The Performance Parameter "Product Quality"}

In order to consider the performance parameter "product quality" at first an appropriate key figure must be determined. This allows an evaluation according to the principle structure of the approach considering a model for quantification. 


\subsection{Derivation of the Key Figure "Adherence to Quality Level"}

In view of networked value-adding, the performance parameter "product quality" can only focus on the quality of one (sub)product, i.e. the quality of the product in each value-adding step or the quality of the realized value added can be evaluated. This is in each case accomplished by independent organization units that are part of the value-adding process. Formulating an appropriate key figure for the quantification of the performance parameter "product quality" appears to be comparatively complicated. Although the quality of a product is a quantifiable characteristic, a problem arises for the specific consideration in the context of the performance analysis, which results from the definition of the term "quality" according to ISO 9000: Quality is the entirety of properties and characteristics of a given product or activity relating to its fitness to fulfill certain requirements. This definition illustrates that for the quality evaluation of a product or subproduct a clarification regarding the product's purpose and the requirements to be fulfilled is obligatory. This is the prerequisite for the features and characteristics of the product that are included in the quality evaluation. It quickly becomes clear that this situation represents a classic use case of the value benefit analysis since the utility value (quality) of an object (product) can ultimately be determined with weighted characteristics (features and characteristics) in an multi-criteria target system (fitness to fulfill given requirements). Hereinafter, the problem for the application field at hand is the necessity to perform a separate value benefit analysis for each value-adding step of a product since each product status has to fulfill certain requirements and, therefore, shows specific characteristics. This results in a significant effort, especially because determining the associated quality criteria weights requires an interaction with the evaluator or decision maker. Furthermore, the weighting function for the characteristics has to be determined, and an independence examination of the characteristics needs to be performed, which is not at all less time-consuming. Still, for the time being this approach comes in handy as it offers the possibility to conduct different weightings of single characteristics and to determine a rooted key figure for the quality on a wide base. However, in the context of the performance analysis of a value-adding process-related production network, the effort associated with a value benefit analysis seems reasonable.

In this case, the weightings and utility value functions of the single quality characteristics are determined once and beforehand for each value-adding step and are always available for future use. A further simplification can be achieved by consolidating similar products in product groups and, thus, performing the value benefit analysis only with due regard to the appropriate product group. However, this approach limits the quality of the evaluation since certain characteristics are neglected due to the subordination in a group. If the groups and the composition of their characteristics are selected skillfully, reliable conclusions regarding the quality in the particular status should, nevertheless, be determinable. Consequently, for the key figure "adherence to quality level" the following mathematical relationship is relevant:

$$
q_{i}=\sum w_{k} \cdot e_{i k}
$$


The degree of the quality performance of a product $q_{i}$ results from the sum of all of this product's degrees of criteria fulfillment $e_{i k}$ multiplied with the corresponding weight of criterion $w_{k}$. Index $i$ represents the producing enterprise and index $k$ the respective criterion. That approach is universally applicable however it has to be evaluated in detail whether it is suitable for the situation. Alternatively there is the possibility of using a binary evaluation as a simplification. When using a binary quality evaluation, criteria weighting and utility value function can be omitted, there is only a differentiation between criterion meets required level (1) or not (0). However this option will not discussed in a detailed way. It is obvious that quality can only be analyzed to a relatively exact degree by investing comparatively high effort. Building groups of single criteria offers an excellent possibility to reduce effort. In many cases, a mixed strategy will ultimately turn out to be the most meaningful approach. If the quality evaluation has to be performed with only a few and/or very inconsistently weighted criteria in all value-adding steps, a value benefit analysis should be used.

The evaluation method to be used should be determined by a basic agreement either before a cooperation is materialized or at the beginning of the cooperation at the latest. If the value benefit analysis is applied, it is important that the weights and the utility value functions for the single criteria per product and the independence of the criteria are considered beforehand. To verify the utility value functions, these midterm reviews should afterwards be checked for plausibility. Only when there are satisfactory evaluation results, it can be assumed that the utility value function really comes close to the actual process of the overall objective and can be used as the basis for the weights determination. To avoid an opportunistic behavior of the enterprise during the determination of the weights and the utility value function, all members of the network or the resource pool should be involved in the process. This opens up the possibility to generate the weights of the criteria from the average value of a wealth of weighting proposals and to, thus, get an evaluation that is supported by all actors.

\subsection{Measurement of the Key Figure "Adherence to Quality Level"}

The quality evaluation has to be performed by the ingoing quality inspection of the receiving enterprise. The result of this evaluation must then be stored in a central repository. However, if this is done by the network management, the respective enterprise gains a certain authority, i.e. only this enterprise decides about the rating that the delivering enterprise gets with regard to quality. To handle possible manipulation tendencies from the beginning on, it is recommended to let the delivering company perform their own outgoing quality inspection with their own data. In doing so, a second quality value can be generated for comparison purposes. If the values of the delivering and the receiving company vary significantly, there is most likely an error within the evaluation process. This can be the result of inaccurate data used for the evaluation or a conscious falsification of the results. In such cases, it is the network management's responsibility to demand the exact single values for the evaluation criteria from all enterprises that are involved in the evaluation. This provides the possibility to subsequently identify the reason for the differences in the evaluation. As a downside of this approach it must be mentioned that in case of a non- 
conformance of the evaluation results a manual intervention is necessary which requires the investment of time and money.

The enterprises involved must dissolve possible differences by mutual agreement and offer a common and consistent evaluation based on the insights and results gained. This in turn facilitates the communication between the decision makers of the enterprises and delivers numerous insights for the evaluation of the cooperation which have an influence on other performance parameters such as "quality of the collaboration and cooperation". If the problem cannot be resolved through communication and agreements, the network management might, if applicable, initiate a revaluation by a neutral authority which then makes a binding decision in form of an evaluation. Should this approach not lead to a decision either - because an appropriate arbitration would take too long or cannot be conducted due to a lack of data - there is finally the possibility to not include quality in the evaluation or to choose an average value as empirical value as an exception.

\subsection{Evaluation of the Key Figure "Adherence to Quality Level"}

The performance parameter "quality" with its key figure "adherence to delivery quality" has a result interval that is mostly precisely predefined and often very limited since it has already been determined with the utility benefit analysis and usually presents ratings between 0 and 10 . Subsequently, it must only be determined if the quality is linked linearly to the degree of target fulfillment or if an alternative curve shape in form of an appropriate mathematical function seems to be more reasonable. This also depends in large part on the strategic decisions of the entire network and the enterprises involved. Independent from the selected correlation between the work performed and the score evaluation an adequate function must be designed. In general, this is expressed as follows:

$$
f_{i}^{Q}\left(q_{i}\right)=x_{i}^{q}
$$

Thus, a specific aggregated weighted score evaluation $q_{i}$ for the performance parameter "quality" leads to a precisely defined evaluation score $x_{i}{ }^{q}$ which is afterwards included in the overall evaluation in form of the performance analysis. In detail, the modeling of this mathematical function also depends on the strategic direction of the network and its members.

If the network, for example, defines quality leadership as their main target, a high number of points has to be deducted from the maximum score, even when there are only minor quality defects present, to ensure target fulfillment. However, if the network aims to achieve price leadership, it can be assumed that the quality has to meet only certain minimum requirements. In this case, (minor) quality defects do not have to be followed by major score deductions. Thus, high degrees of target fulfillment can be given even if there are relatively low quality values present. When using the utility benefit analysis for the quality evaluation, already a medium-level degree of target fulfillment (e.g. a score of 6 or 7) can, depending on the evaluation function, lead to the assumption that, for example, many less important or a few important criteria were not adhered to with regard to their tolerance values. 
For simplification purposes it can be assumed that for the usage of the value benefit analysis all degrees of target fulfillment up to a certain value (e.g. 7) indicate the adherence to the tolerance values, i.e. up to a degree of target fulfillment of 7 the binary method still provides an "OK" rating (1), below that the rating is 0 . In this case, a score around 7 would, thus, be the critical degree of fulfillment. This results in a 3 point maximum overvaluation of the binary method if all values are rated with 7 in the value benefit analysis. With the binary method this would add up to a 10 point degree of target fulfillment. On the other hand, if all criteria are rated with 6 points in the value benefit analysis, this results in a 0 rating in the binary method. If notably high (good) or low (bad) ratings are achieved with the binary method, the result should be validated in any case since there might exist falsifications in the rating scale.

\subsection{Analysis of the Key Figure "Adherence to Quality Level"}

The examples outlined above illustrate that the evaluation of the performance parameter "quality" based on the two possibilities presented can result in significantly different results. Several random ratings of 10 criteria demonstrated that the results achieved with the binary method can in favorable cases vary by 0.5 points from the result of the value benefit analysis. Unfortunately due to the limited space an example cannot be given in this contribution.

If for the quality rating the value benefit analysis is preferred, the subsequent application of Lagrange interpolation might be appropriate to determine an adequate utility value function and hence a weighting function. Finally, it should be noted that a utility value function can be determined more precisely if more points are included in the interpolation. However, their degree also rises to the same extend which leads to a rapid increase of complexity. Furthermore, care must be taken to ensure that the function in the interval in question does not assign negative degrees of target fulfillment. Nevertheless, in case of an unfavorable choice of points this cannot be eliminated entirely. This problem can be solved by zeroing in negative degrees of fulfillment.

Consequently, as an interim result, an appropriate weighting function is created that makes it possible to deliver a score evaluation for the entire value spectrum of possible aggregated degrees of fulfillment for the performance parameter "quality". This score evaluation is included in the performance analysis of all performance parameters to be considered and will in turn be weighted for this purpose. The reduction to one single value for the rating of a performance parameter on the basis of a predefined key figure presents the core element of the value-adding process-related performance analysis. In this context, it must be ensured that in the modeling process possible minimum degrees of fulfillment are always taken into consideration. Furthermore, if a quality criterion is not met, this cannot be offset by the aboveaverage fulfillment of another quality criterion. That fact is important to avoid tendencies for substitution of lacking quality to one criterion with outstanding quality of another criterion. It must be ensured that every criterion representing product quality reaches a certain level. 


\section{Conclusions}

This contribution introduces a framework for an approach for the measurement, evaluation and analysis of the performance parameter "product quality" by the application of the key figure "adherence to product quality". Under consideration of two different models for possible cases, a specific evaluation function can be determined by the application of Lagrange interpolation. These allow for the modeling of a calculation scheme depending on the degree to which the agreed quality level is met. With the inclusion of that framework, a major step towards a sustainable success of a network is accomplished because a very short-term analysis is possible. This allows for countermeasures in case of an unsatisfactory performance. The approach presented in this contribution is a theoretical model. Unfortunately an example cannot be given to provide a general understanding because lack of space. This approach represents a universal concept for a performance analysis that relates to the value-adding process and can be applied for enterprises operating in enterprise networks. It allows for a comprehensive analysis of the service performed by an enterprise based on selected performance measures. Efforts regarding the testing and realization from an IT point of view are being made currently and represent the actual challenge. In this context, the aim is the continuous improvement of the approach.

\section{References}

1. Jähn, H.: Value-adding process-related performance analysis of enterprises acting in cooperative production structures. Production Planning \& Control 20 (2), 178--190 (2009)

2. Jähn, H.: Leistungsanalyse und Gewinnverteilung in vernetzten Produktionsstrukturen Möglichkeiten im Rahmen des Extended Value Chain Management-Ansatzes. Dr. Kovac, Hamburg (2008)

3. Neely, A. (ed.): Business Performance Measurement, 2nd Ed., Cambridge University Press, Cambridge (2007)

4. Lyons, A.C., Coronado Mondragon, A.E., Piller, F., Poler, R.: Customer-Driven Supply Chains From Glass Pipelines to Open Innovation Networks, Springer, London (2012)

5. Chendall, R.H., Langfield-Smitz, K.: Multiple Perspectives of Performance Measures. European Management Journal 25 (4), 266--282 (2007)

6. Brewer, P., Speh, T.: Using the balanced scorecard to measure supply chain performance. Journal of Business Logistics 22 (1), 75--93 (2000)

7. Gunasekaran, A., Patel, C., McGaughey, R.E.: A framework for supply chain performance measurement. Int. J. Production Economics 87, 333--347 (2004)

8. Bhagwat, R., Sharma, M.H.: An application of the integrated AHP-PGP model for performance measurement of supply chain management. Production Planning \& Control 20 (8), 678--690 (2009)

9. Westphal, I., Thoben, K.-D., Seifert, M.: Measuring Collaboration Performance in Virtual Organizations. In: Camarinha-Matos, L.M. et al. (eds.) Establishing the Foundation of Collaborative Networks. pp. 33--42, Springer, Boston (2007)

10. Lockamy III, A.: Quality-focused performance measurement systems: a normative model. International Journal of Operations \& Production Management, 18 (8), 740--766, 1998 